\title{
Microcirculation versus Macrocirculation for the Management of Septic Shock: Is Hyperoxia any Good?
}

Ata Mahmoodpoor ${ }^{1}$, Daryoush Sheikhzadeh ${ }^{1}$, Samad EJ Golzari $^{{ }^{*}}$

1. Department of Anesthesiology and Intensive Care Medicine, Tabriz University of Medical Sciences,

Tabriz, Iran

Macrovascular indices such as hemodynamic parameters and conventional cardiovascular support measures are commonly, yet mistakenly used, for the clinical management of septic shock. Nevertheless, it is the microcirculatory dysfunction that contributes immensely to the development of septic shock. Approaches focusing on macrocirculation rather than microcirculation utterly neglect 'what lies beneath' in the microcirculation (1). The most important known mechanisms contributing to the pathophysiology of severe sepsis are but not limited to"microcirculatory and mitochondrial distress syndrome" (MMDS) (2), global tissue rather than arterial hypoxia (3), generalized endothelial cell injury (4), and activation of the coagulation cascade (5). Therefore, setting macrocirculation parameters such as arterial oxygen saturation as the ultimate goal of resuscitation in septic patients (6) not only would not be associated with any benefits but also harm the patients. Moreover, it might falsely reassure the clinicians that the patients are in clinically stable state and overlook 'what lies beneath'.
Hyperoxia was initially believed to exert vasoconstrictor properties, thus potentially allowing for haemodynamic stabilisation in vasodilatory shock. Nevertheless, it has been shown that normobaric hyperoxia decreases the capillary perfusion and VO2 max (the maximum rate of oxygen consumption) and increases the heterogenisity of perfusion (7). Accordingly, some studies revealed that hyperoxia increases the risk of multi-organ failure in sepsis (8). Microcirculatory and cellular factors and tissue diffusion influence oxygen status of cells and supranormal $\mathrm{O}_{2}$ delivery can compensate for neither the diffusion impairment existing between capillaries and cells, nor for the intracellular metabolic dysfunction (9). Therefore, oxygen therapy should be managed cautiously during sepsis to minimize its probable deleterious effects (8). This might be achieved through personalized oxygenation based on the repeated assessments of ongoing oxygen requirements and implementation of strategies reducing metabolic rate and improving tissue oxygenation.

\section{Corresponding author:}

Samad EJ Golzari, MD

Department of Anesthesiology and Intensive Care Medicine, Tabriz University of Medical Sciences, Tabriz, Iran E-mail: dr.golzari@hotmail.com Tel: 00989141151894

Receive date: 2017-01-24 | Accept date: 2017-03-26 | Publish date: 2017-04-08

DOI: 10.7575/aiac.abcmed.17.05.02.01

\section{A. I}




\section{References}

1. Bateman RM, Sharpe MD, Ellis CG. Bench-to-bedside review: microvascular dysfunction in sepsis - hemodynamics, oxygen transport, and nitric oxide. Crit Care. 2003;7:359-373

2. Ince C. Microcirculation in distress: a new resuscitation end point? Crit Care Med. 2004;32:1963-1964. doi: 10.1097/01.CCM.0000139617.88704.B9.

3. Bateman RM, Sharpe MD, Ellis CG. Bench-to-bedside review: microvascular dysfunction in sepsis - hemodynamics, oxygen transport, and nitric oxide. Crit Care. 2003;7:359-373. doi: 10.1186/cc2353

4. Aird WC. The role of the endothelium in severe sepsis and multiple organ dysfunction syndrome. Blood. 2003;101:3765-3777. doi: 10.1182/blood-2002-06-1887.

5. Rivers E, Nguyen B, Havstad S, et al. Early Goal-Directed Therapy Collaborative Group. Early goal-directed therapy in the treatment of severe sepsis and septic shock. $N$ Engl J Med. 2001;345:1368-1377. doi: 10.1056/NEJMoa010307.

6. Asfar P, Schortgen F, Boisramé-Helms J, et al. Hyperoxia and hypertonic saline in patients with septic shock (HYPERS2S): a two-by-two factorial, multicentre, randomised, clinical trial. Lancet Respir Med. 2017 Feb 14. pii: S2213-2600(17)30046-2. doi: 10.1016/S2213-2600(17)30046-2.

7. Orbegozo Cortés D, Puflea F, Donadello K, et al. Normobarichyperoxia alters the microcirculation in healthy volunteers. Microvasc Res. 2015 Mar;98:23-8. doi: 10.1016/j.mvr.2014.11.006.

8. Rodríguez-González R, Martín-Barrasa JL, Ramos-Nuez Á, et al. Multiple system organ response induced by hyperoxia in a clinically relevant animal model of sepsis. Shock. 2014 Aug;42(2):148-53. doi: 10.1097/SHK.0000000000000189.

9. Leach RM1, Treacher DF. The pulmonary physician in critical care *2: oxygen delivery and consumption in the critically ill. Thorax. 2002 Feb;57(2):170-7. 